\title{
Acoustic detection and quantification of benthic egg beds of the squid Loligo opalescens in Monterey Bay, California
}

\author{
Kenneth G. Foote \\ Woods Hole Oceanographic Institution, Woods Hole, Massachusetts 02543 \\ Roger T. Hanlon \\ Marine Biological Laboratory, Woods Hole, Massachusetts 02543
}

Pat J. lampietro and Rikk G. Kvitek

California State University Monterey Bay, Seaside, California 93955

(Received 12 May 2005; revised 13 October 2005; accepted 15 November 2005)

\begin{abstract}
The squid Loligo opalescens is a key species in the nearshore pelagic community of California, supporting the most valuable state marine fishery, yet the stock biomass is unknown. In southern Monterey Bay, extensive beds occur on a flat, sandy bottom, water depths 20-60 m, thus sidescan sonar is a prima-facie candidate for use in rapid, synoptic, and noninvasive surveying. The present study describes development of an acoustic method to detect, identify, and quantify squid egg beds by means of high-frequency sidescan-sonar imagery. Verification of the method has been undertaken with a video camera carried on a remotely operated vehicle. It has been established that sidescan sonar images can be used to predict the presence or absence of squid egg beds. The lower size limit of detectability of an isolated egg bed is about $0.5 \mathrm{~m}$ with a $400-\mathrm{kHz}$ sidescan sonar used with a $50-\mathrm{m}$ range when towed at 3 knots. It is possible to estimate the abundance of eggs in a region of interest by computing the cumulative area covered by the egg beds according to the sidescan sonar image. In a selected quadrat one arc second on each side, the estimated number of eggs was 36.5 million. () 2006 Acoustical Society of America. [DOI: 10.1121/1.2149840]
\end{abstract}

PACS number(s): 43.30.Gv, 43.30.Sf, 43.30.Xm, 43.80.Jz [WMC]

Pages: $844-856$

\section{INTRODUCTION}

\section{A. Ecological and economic importance of Loligo opalescens}

Squids, which are cephalopod mollusks, are key players in many marine ecosystems, both as predator and prey. ${ }^{1}$ Loligo opalescens is a major prey species in the central and southern California coastal ecosystem. In Monterey Bay, juvenile and adult squids of this species are important food items in the diets of 19 fish, nine bird, and two marine mammal species. ${ }^{2}$ According to this enumeration, Loligo opalescens has the greatest number of predator species in the particular nearshore pelagic ecosystem.

Loligo opalescens supports the most valuable marine fishery in California. This fishery is 140 years old, ${ }^{3,4}$ has quadrupled in the past decade, and is estimated to be at maximum exploitation, yet no fishery management plan has existed until autumn 2004. ${ }^{5,6}$ The management plan is based largely on an "egg escapement model,", and thus it might be useful to learn the extent of actual egg laying in any given season or year. Most loliginid squids, such as Loligo opalescens $^{3}$ and Loligo vulgaris reynaudii, ${ }^{8}$ are among the very few marine species that deposit their gelatinous egg capsules in mops directly on the substrate, thus rendering their spatial distribution immediately accessible to direct measurement.

Timely, synoptic data on the spatial distribution and abundance of Loligo opalescens in Monterey Bay are of particular interest both for management and for understanding the ecology, including that of the larger Monterey Bay
National Marine Sanctuary. Given accessibility of the squid, acoustics would appear to be a useful tool for such work.

\section{B. Overview of acoustic methods to quantify squid}

Traditionally, several direct and indirect methods have been employed to assess squid stocks. These methods include, for example, those based on catch-per-unit effort (CPUE) and swept area of bottom trawl, with various applications to Loligo pealeii, ${ }^{9}$ Loligo forbesi, ${ }^{10}$ and Loligo gahi. ${ }^{11}$ Known difficulties in assessing demersal fish by bottom trawl ${ }^{12,13}$ also apply to squid. Use of pelagic trawl or plankton net is also difficult, as when surveying cephalopod larvae, including Loligo opalescens larvae, ${ }^{14}$ to achieve adequate areal coverage. Some aspects of fishery dynamics have been measured remotely to yield a proxy for fishing effort, thence enabling abundance to be assessed indirectly through a landings-per-unit-of-effort (LPUE) measure. ${ }^{15}$ The method of biomass estimation by enumerating squid beaks in the stomachs of predators is known to be problematical. ${ }^{16}$ For Loligo opalescens, egg and larval surveys have not succeeded. ${ }^{17}$ The potential of camera-based surveys has been recognized, but principally for quantification of benthic eggs rather than swimming animals that may avoid lights. ${ }^{17}$ Other, generic difficulties apply, including that of efficiency when having to survey a rather large area with an instrument dependent on underwater visibility. Advantages of the direct acoustic surveying method for general fisheries applications are thus appreciated: they are rapid, remote, noninvasive, synoptic, and quantifiable. ${ }^{13,18}$ General disadvantages of 
acoustic methods are associated with detection, identification, and knowing the applicable characteristic scattering properties of individual organisms in order to be able to reduce acoustic measures of organism density to biological measures of concentration density. Specific disadvantages for squid according to Thorne and Starr ${ }^{19}$ are those of nearbottom detection, identification without having recourse to other means, and quantification in the presence of avoidance behavior or in the case of dense schools causing extinction.

The feasibility of estimating squid stock abundance by acoustic means has been established in a number of studies, including demonstrations through sea trials. Examples are Loligo gahi and Martialia hyadesi on the Falkland Shelf in the South Atlantic ${ }^{20}$ and Loligo vulgaris reynaudii off the south coast of South Africa. ${ }^{21}$ Acoustic data were derived from echo sounders with vertically oriented beams at 38 and $120 \mathrm{kHz}$ for the first two species and at $38 \mathrm{kHz}$ for the third species. In recent years, the abundance of Todarodes pacificus on the major fishing ground off northern Honshu, Japan, has been estimated at $38 \mathrm{kHz}$ by the echo integration method (Ref. 22 and A. Kawabata, pers. comm.). Acoustic trials are also being performed on the same species around Hokkaido, Japan, and on Loligo edulis in the East China Sea (A. Kawabata pers. comm.).

The acoustic detectability of Loligo opalescens aggregations in the water column was established by Vaughan and Recksiek $^{23,24}$ in Monterey Bay. Several distinctive echo types were observed at 38,50,75, and $200 \mathrm{kHz}$. These were associated with proximity to the bottom and time of day.

Loligo opalescens has also been observed acoustically off the central Oregon coast by Jefferts et al. ${ }^{25}$ This was quantified by means of integration of echo sounder data at $120 \mathrm{kHz}$. In addition, the target strengths of resolved individual squid were measured directly by means of the dualbeam function of the same echo sounder. ${ }^{26}$

\section{Biology of Loligo opalescens}

Loligo opalescens is very fast-growing, short-lived, and highly mobile, as described in, for example, Refs. 3 and 27-30. Little is known in detail about its whereabouts for much of its life history. The exceptions are the end points defined by spawning. Near the end of its 6-12 month life span, Loligo opalescens migrates inshore and spawns, laying eggs in capsules on the shallow coastal seafloor. After about one month, paralarvae, which are morphologically similar to the adult, emerge from the capsules to enter the plankton stage; their movements are generally unknown. ${ }^{31}$ Those individuals that survive predation and other forms of mortality return as adults to spawn. Significantly for acoustic investigations, the egg laying seems to occur mainly on flat sandy bottoms in depths of $20-60 \mathrm{~m}^{31-37}$

The eggs are laid in gelatinous capsules containing 100200 eggs, each in its own Voronoi-like cell ${ }^{38}$ called a chorion. Initially, the capsules are cylindrical in form, $c a$. $16 \mathrm{~mm}$ in diameter and about $9-10 \mathrm{~cm}$ long, expanding to 20-25 cm after a few days. ${ }^{39}$ The female cements each capsule in the sand, and they stand vertically, bending and swaying under the influence of currents. The presence of egg cap- sules attracts other spawning squid, which tend to deposit their egg capsules contiguously with existing capsules. In this way, benthic egg mops of diameter $20-100 \mathrm{~cm}$ and $e g g$ beds of diameter greater than $1 \mathrm{~m}$ are formed (Fig. 1). For simplicity, these are often referred to generically as egg beds. These can become massive, reaching $12 \mathrm{~m}$ in extent, ${ }^{39}$ and may even consist of multiple tiers rising $40-60 \mathrm{~cm}$ off the sea floor or, as reported anecdotally in Ref. 3 , in a pillar $1.5-\mathrm{m}$ high. Hatching occurs about one month after egglaying, depending upon temperature. ${ }^{28}$ The period of peak spawning in Monterey Bay is thought to coincide with peak fishery catches during April-May. Squids continue to be fished through the summer, with a secondary capture peak in September-October. ${ }^{6}$ Eggs are present throughout this period. One record exists of the presence and absence of eggs following an El Nino event; ${ }^{40}$ however, no maps are published of egg distribution or abundance, either yearly or seasonal.

The primary spawning grounds of Loligo opalescens in central California are located in the southern part of Monterey Bay over an area that is about $10 \mathrm{~km}^{2}$. This is small compared to the larger habitat, but is still large for detailed surveying. Currently, the State of California closes
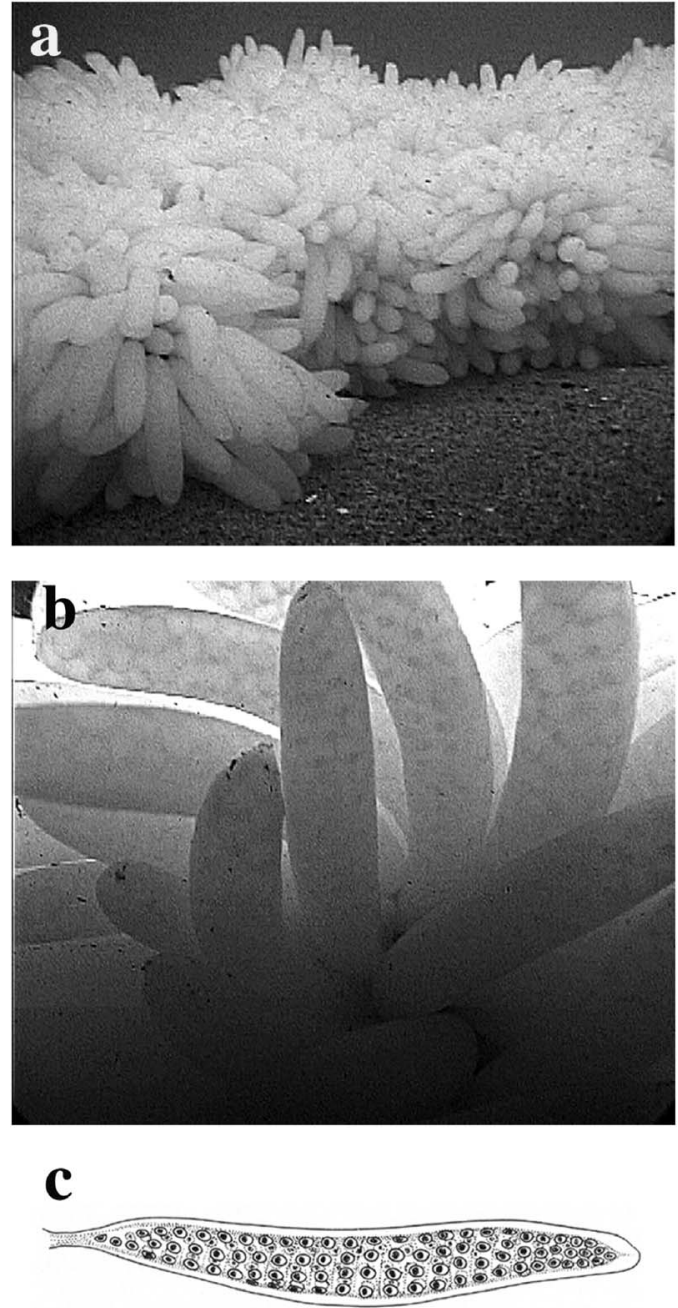

FIG. 1. Egg bed of the squid Loligo opalescens. (a) Section of egg bed. (b) Detailed view. Individual chorions can be seen. (c) Sketch of egg capsule [redrawn from C. F. E. Roper, Bull. Mar. Sci. 15, 589-598 (1965)]. 
squid fishing two days per week, ${ }^{35}$ but no benthic habitat for squid egg beds is protected. Successful annual recruitment is required to sustain squid populations. ${ }^{41}$ If fishing pressure continues to increase, it may be prudent to restrict fishing directly over the largest egg beds to allow the normal progression of sexual selection and egg-laying behaviors. ${ }^{34,37}$

\section{Acoustic technology}

The unique loliginid habit of laying massive benthic egg beds can be exploited in surveying egg beds and thus using egg capsule production as a proxy for reproductive success. Certainly the advantages of surveying a stationary resource and performing analyses based on spatial information are both prominent and tempting in choosing a method. To meet the requirements of resolution and detectable backscatter, it would seem that a sonar with a very directional beam and rather low grazing angle relative to the bottom would be most effective; this defines a towed, high-frequency sidescan sonar. ${ }^{42,43}$

\section{E. Outline of this paper}

The plan of this work is to describe development of an acoustic method to detect, identify, and quantify egg beds of Loligo opalescens. In the following, preliminary investigations on squid egg capsules and beds are summarized. The design of an experiment to verify the acoustic method is elaborated. Details are given on the instrumentation, equipment, platforms, and methods. Video and acoustic images of the same regions of interest are included in the results. The abundance of eggs is estimated in a quadrat that is one arcsecond on each side. Outstanding problems connected with acoustic resolution, use of alternate platforms, automated recognition of egg-bed echoes, squid biology, monitoring of squid spawning grounds, and acoustic properties of egg capsules are discussed.

\section{PRELIMINARY ACOUSTIC OBSERVATIONS OF SQUID EGG BEDS}

Acoustic detectability of egg capsules of Loligo pealeii was established at the Marine Resources Center, Marine Biological Laboratory, by two of the authors (KF and RH), together with J. Condiotty and C. Gubala in June 2002. Egg capsules freshly laid by the squid in a mop on the bottom of a tank, water depth $80 \mathrm{~cm}$, were observed with the Simrad EY500/710-kHz echo sounder, with transducer floating on the water surface, using a short-duration pulse. Loligo pealeii, like Loligo opalescens, attaches its egg capsules to the bottom substrate, preferring to abut previously laid capsules. Relative to the echo from the bottom of the tank, the echo from the capsules arrived earlier by a time corresponding to the height of the capsules, $8 \mathrm{~cm}$. Despite the particular $e x$ situ conditions, this measurement gave tangible proof that egg capsules of squid could be detected acoustically.

In a study by Sauer et al., ${ }^{44}$ some evidence was presented for the acoustic identification of Loligo vulgaris reynaudii egg beds in situ. A commercial fisheries echo sounder, with operating frequency of $200 \mathrm{kHz}$, was used. While the identification probability was very high under the circum- stances, it is not clear that the significant part of the echo was due to the egg beds themselves and not to bottom morphological features or spawning squid in the vicinity of the egg beds.

The initial acoustic investigation in the field was conducted in May 2003 in Monterey Bay. A 400-kHz sidescan sonar was towed from the California Department of Fish and Game (CDFG) research vessel Mako. Within minutes of commencing the first sidescan sonar transect off Del Monte Beach, with bottom depth of 20-30 m, a distinct dapple or mottling was observed on the sidescan sonar echo record. The size, shape, and proximity of the small features were reminiscent of squid egg beds that SCUBA divers in the scientific party had earlier observed.

Because of the proximity of the beach and exposure of the site to the open ocean, a second site was visited, just north of the breakwater and several hundred meters off Cannery Row. The sidescan sonar observations were similar to those off the beach. SCUBA divers descended to confirm a large concentration of squid egg beds. Various attempts were made to establish a close correlation of the sidescan sonar recordings and squid egg beds. Navigation was a limiting factor, but the results were strongly suggestive.

Efforts to detect the squid egg beds with the Simrad EK60 scientific echo sounder, ${ }^{45}$ the successor to the EK500 scientific echo sounder, ${ }^{46}$ with split-beam transducer at $200 \mathrm{kHz}$, were unsuccessful. Echoes from the egg beds and bottom could not be distinguished, which is not surprising, given the pulse length $10 \mathrm{~cm}$, nominal $9-10 \mathrm{~cm}$ height of newly laid egg capsules, bottom depth of 20-30 m, sea state, and vessel mounting of the transducer.

A second acoustic investigation in the field was performed about the Channel Islands in southern California in late February and early March 2004. A $600-\mathrm{kHz}$ sidescan sonar was towed from the NOAA Channel Islands National Marine Sanctuary research vessel Shearwater. This was configured with a video camera, with downward orientation. Squid egg beds were observed simultaneously with both systems, if at different ranges. An unexpectedly strong current dragged a bottom-mounted array of acoustic reflectors including floats, out of alignment, preventing repeated observations of the reflectors and squid egg beds.

\section{EXPERIMENTAL DESIGN}

Based on the preceding investigations, with their suggestive findings and association of certain characteristic features on the sidescan sonar image and squid egg beds, it was decided to perform a larger-scale verification trial on the spawning grounds in Monterey Bay. The principal acoustic instrument would be a high-frequency sidescan sonar with integrated geo-referencing processing system. The major verification tools would be video cameras. One would be a drop camera, to be suspended over the side of the vessel for reconnaissance use, and the second would be ROV-borne for investigations with a relatively high degree of operator control.

Initially, a region of high concentration of egg beds had to be found. This was done by means of the drop camera 
over traditional spawning areas. A survey region of interest (roi) was defined. This was surveyed systematically by sidescan sonar along parallel transects, as in Refs. 47 and 48, with substantial overlapping coverage to enable a map, or mosaic, of seafloor backscattering to be assembled.

Locations with markings suggestive of squid egg beds were noted. Following the sidescan sonar survey, the same roi was surveyed by means of a ROV-borne video camera. The degree of coverage was much less, but the entire roi was sampled along a few transects. The ROV was steered to investigate previously identified areas of special interest.

Precision navigation instrumentation was used. A differential Global Positioning System (dGPS) was used to determine the positions of the sidescan sonar transducer arrays and ROV-borne video camera. An acoustic tracking system was used for precise determination of the position of the video camera relative to the vessel.

Given both sonar and video data on the roi, tests were devised to prove that characteristic sidescan sonar features could be associated unambiguously with the presence or absence of egg beds. Two tests were designed, one with the sidescan sonar data enabling predictions to be made for verification by the video-camera images, and vice versa. Statistics could then be employed to assign significance levels.

In addition, the sidescan sonar data provided the grist for quantification of the egg beds within a defined area. This served as an example of the feasibility of abundance estimation.

\section{MATERIALS}

\section{A. Acoustic instrumentation}

\section{Sidescan sonar}

The principal acoustic instrument was the EdgeTech model 260-TH Image Correcting Side Scan Sonar, with model 272-TD dual-frequency analog towed vehicle, called a towfish, with time-varied gain (TVG). This was used to detect and image the squid egg beds. Two longitudinally oriented, parallel transducer arrays were mounted on each side of the towfish, with nominal operating frequencies of 100 and $500 \mathrm{kHz}$, as casually described by the manufacturer, but with the higher frequency being much closer to $400 \mathrm{kHz}$. A deck unit supplied power to the towfish, controlled this, printed the paper record, and sent the analog signal to the Isis Sonar digital acquisition system contained in the model 260-TH Image Correcting Side Scan Sonar.

Both frequencies were used. The upper frequency was in the range $390 \pm 20 \mathrm{kHz}$. The pulse duration was $0.01 \mathrm{~ms}$. At 50 - $\mathrm{m}$ range, the ping interval was $75 \mathrm{~ms}$, hence the ping rate was $13 / \mathrm{s}$.

The sampling frequency was 2048 16-bit pixels per channel per second, as determined by the AU-32 A/D board in the Isis acquisition system, not the sonar, which was entirely analog. The source level was $222 \mathrm{~dB}$ re $1 \mu \mathrm{Pa}$ at $1 \mathrm{~m}$. The horizontal beamwidth was $0.5 \mathrm{deg}$ at the $-3 \mathrm{~dB}$ level, and the vertical beamwidth was $50-\mathrm{deg}$, tilted downward by $20 \mathrm{deg}$ from the horizontal.

The lower frequency was $105 \pm 10 \mathrm{kHz}$. The pulse dura- tion was $0.1 \mathrm{~ms}$. At $50-\mathrm{m}$ range, the ping interval, ping rate, and sampling frequency were the same as for the higher frequency, but the source level was $228 \mathrm{~dB}$ re $1 \mu \mathrm{Pa}$ at $1 \mathrm{~m}$. The horizontal beamwidth was $1.2 \mathrm{deg}$, and the vertical beamwidth was $50 \mathrm{deg}$, tilted down $20 \mathrm{deg}$ from the horizontal.

\section{Fishing echo sounder}

A Furuno Fish Finder, model FCV582L echo sounder, was used for general inspection of the water column and occasional detection of squid aggregations in advance of sonar or video observations of egg beds and part of the water column. The echo sounder operated at both 50 and $200 \mathrm{kHz}$, with a nominal maximum range of $750 \mathrm{~m}$ at the lower frequency, with $600-\mathrm{W}$ output power. Echo data were converted to a video signal and displayed on a color liquid crystal display (LCD). Automatic gain control was used but not monitored.

\section{B. Video cameras}

\section{Drop camera}

The reconnaissance camera was suspended on a weighted line from the vessel. This was the Deep Blue Pro Color camera, which forms a National Television System Committee (NTSC) composite video image with $480 \mathrm{TV}$ lines. This was a compact unit, with $3.6-\mathrm{mm}$ wide-angle lens, focus fixed at $2.54 \mathrm{~cm}$ to infinity, sensitivity 0.3 lux, and electronic iris. Image data were transferred by cable to the vessel and stored on a JVC BR-DV600A mini-digital video camera recorder (VCR). Telemetry and other information were overlaid on the video image.

\section{ROV-carried camera}

The camera used in the verification exercises was that mounted inside the remotely operated vehicle (ROV): a JVC model with 470-lines resolution, 0.95-lux color chargecoupled device (CCD) and F 0.8 Pentax lens. Through its internal mounting, it could tilt and view through $360 \mathrm{deg}$. Panning of the camera was achieved by rotating the vehicle, which could turn on its own axis. Image data were transferred through the ROV tether and, as with the drop camera, recorded on an on-board JVC BR-DV600A mini-digital VCR.

\section{Platforms and positioning devices \\ 1. Research vessel MacGinitie}

The principal platform was R/V MacGinitie, an aluminum hydrographic survey launch, overall length $9.6 \mathrm{~m}$, draft $0.5 \mathrm{~m}$, beam $2.7 \mathrm{~m}$, gross weight 4.5 metric tons fully equipped, cruising speed 18-28 knots depending on conditions, electrical power $30-\mathrm{A} 110-\mathrm{V}$ ac and $12-\mathrm{V}$ dc. It carried state-of-the-art sonar mapping and ROV technology like that found on large hydrographic research vessels, but in a towable configuration designed for nearshore shallow-water habitat work. It is owned and operated by the Seafloor Mapping Laboratory of California State University, Monterey Bay. 


\section{Remotely operated vehicle Hyball}

A platform for the JVC video camera was the Hyball ROV, which has a 300-m depth capability and is fitted with four thrusters. Two main thrusters provide forward, reverse, and rotational movement, and two vertran thrusters provide vertical and lateral movement. This small unit was easy to deploy and retrieve and proved sufficiently maneuverable in depths up to $34 \mathrm{~m}$ with mild or no current.

\section{Positioning systems}

\section{Global Positioning System}

Research vessel MacGinitie has a differential GPS (dGPS). This is fully integrated with the PC-based Nobeltec/ Sitex navigation system of the vessel, which also includes digital charting, radar, and autopilot. Data from the dGPS could be attached to the sonar and video data at the time of their collection.

\section{Trackpoint}

The Hyball ROV was tracked and its position determined by a Trackpoint II+ ultra-short baseline acoustic tracking system (ORE International, Houston, Texas). The Trackpoint system has a $0.5-\mathrm{m}$ slant-range accuracy and a total horizontal position accuracy of less than $0.5 \%$ rootmean square of slant range. Depth information was provided by a pressure sensor on the vehicle as well as by a 4337B Trackpoint multibeacon with depth telemetry. The Trackpoint system was interfaced to the top-side vessel survey navigation system with dGPS and provided real-world $(x, y, z)$-positioning of the ROV with accuracy $\pm 2 \mathrm{~m}$ by means of the Coastal Oceanographics Hypack Max software. The National Marine Electronics Association (NMEA) position data were also recorded directly on the digital video (DV) tape using a Horita GPS-3 encoder. This device recorded the position data in an audio track on the videotape, where they could be accessed without obscuring the video imagery.

\section{FIELD METHODS}

The field work was conducted on the traditional spawning grounds of Loligo opalescens in southern Monterey Bay during the period 13-16 May 2004. This work began with a reconnaissance with the drop camera to locate a region abundant in egg beds. The identified region was then surveyed systematically by sidescan sonar. It was subsequently surveyed by ROV-borne camera to verify the sidescan sonar observations.

\section{A. Drop-camera reconnaissance}

The initial drop-camera reconnaissance was performed on 13 May over a flat sandy bottom off the breakwater and in view of Cannery Row at four stations with the vessel drifting at $0.5-1$ knot. The approximate depth range was $26-34 \mathrm{~m}$. Small numbers of lone squids were observed scattered widely on the bottom, generally in the vicinity of eggs, but neither adults nor eggs were numerous.
The reconnaissance was continued on 14 May, drifting from north of Lovers Point to Hopkins Marine Station at the approximate speed $0.5-1$ knot. The drift path followed that of a fault line, depth difference 6-7 m, dividing an otherwise flat sandy bottom within the depth range $25-40 \mathrm{~m}$. The drift path was maintained near the fault line by use of the vessel motor when necessary. Sparsely and richly populated patches of squid egg beds were observed.

On both days notable features were marked. This operation generated a computer file with paired geographical positions and time codes, as well as biological annotations. The drop-camera position was assumed to be identical to that of the vessel since the camera was suspended from the drifting vessel over a rather short distance, and the line was observed to be vertical.

\section{B. Sidescan sonar survey}

The fault-line area identified by the drop-camera reconnaissance was surveyed with the sidescan sonar on 15 May (Fig. 2). Twenty parallel transects were performed at the speed 2-4 knots with the maximum range of $50 \mathrm{~m}$ to each side of the towed arrays. The sidescan sonar was maintained about 5-10 $\mathrm{m}$ over the seafloor, whose depth varied over the approximate range $25-40 \mathrm{~m}$. The first 15 transects were performed at the upper frequency, about $400 \mathrm{kHz}$, and the last five at the lower frequency, about $100 \mathrm{kHz}$. The first 15 transects were performed with a track spacing of $50 \mathrm{~m}$, ensuring $100 \%$ overlap in the port or starboard swath. Working conditions were characterized by a fresh onshore breeze and short, steep seas of wave amplitude 1-2 m.

\section{ROV-borne video camera investigations}

At the beginning of the field work on 16 May, the vessel flux-gate compass was calibrated in two exercises performed off Cannery Row. This enabled the vessel heading to be determined to within $\pm 1 \mathrm{deg}$. The flux-gate compass was interfaced with the Trackpoint system (Sec. IV D 2), enabling the ROV position to be given in absolute rather than relative coordinates.

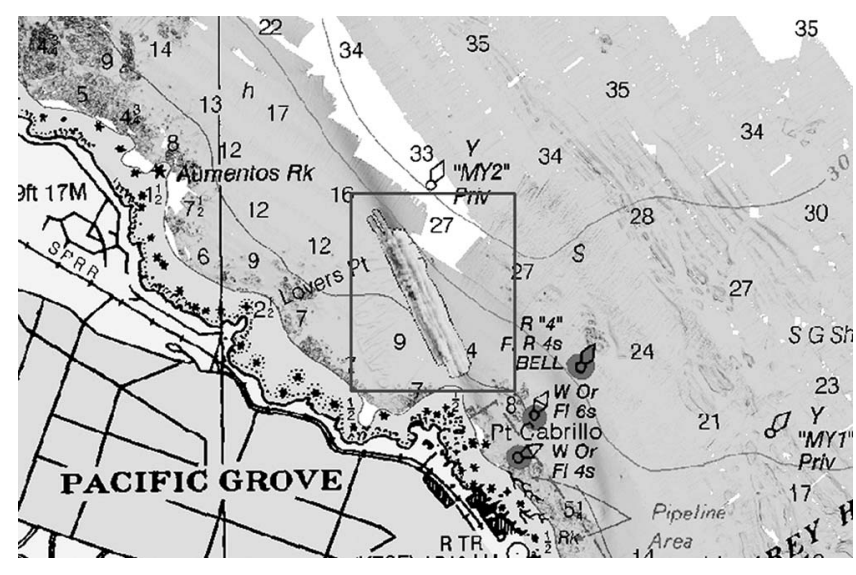

FIG. 2. Geographical region of the sidescan sonar survey off Pacific Grove in southern Monterey Bay on 15 May 2004, showing the high-frequency sidescan sonar mosaic. 
The ROV was deployed with the vessel drifting or motoring gently to maintain a track parallel to the fault line. Three parallel track lines, located within the sidescan sonar survey area, were surveyed, with a nominal separation distance of $20 \mathrm{~m}$. One of the track lines is shown in Fig. 3. Several large, dense aggregations of squid egg beds were circumnavigated in an attempt to map their extents, occasionally exceeding $10 \mathrm{~m}$. The ROV was kept approximately 1-2 $\mathrm{m}$ from the bottom, with a forward/downward viewing angle of approximately $45 \mathrm{deg}$. Video from the ROV was recorded with the JVC unit on mini-digital videotape format. ROV positions were determined using a Trackpoint II+ ultra-short-baseline acoustic tracking system (ORE International, Houston, TX) and the vessel dGPS to yield real-world $(x, y, z)$-coordinates with \pm 2 -m accuracy. The ROV depth was also determined by a pressure sensor mounted on the vehicle. ROV position, pressure-determined depth, and time in UTC were recorded onto the videotape using a Horita GPS-3 encoder.

Lone squids were observed in the vicinity of some egg beds. Occasional pairings and contested pairings were also observed, although the observations of spawning squid were incidental to the objective of surveying the egg beds.

\section{DATA POSTPROCESSING}

Several data processing operations were undertaken in the Seafloor Mapping Laboratory immediately after completion of the cruises.

\section{A. Postprocessing and mosaicking of sidescan sonar data}

Digital processing and mosaicking of the $400-\mathrm{kHz}$ sidescan sonar data were accomplished using the Isis Sonar and Delph Map software packages (Triton Elics International, Watsonville, California) and TNT Mips geographical information system (GIS) software (Microimages, Inc., Lincoln, Nebraska). Individual xtf track-line files were replayed, and bottom tracking of the sonar was supervised to aid in proper slant-range correction. Line files were snipped to remove portions with poor imagery from the beginning and/or end of

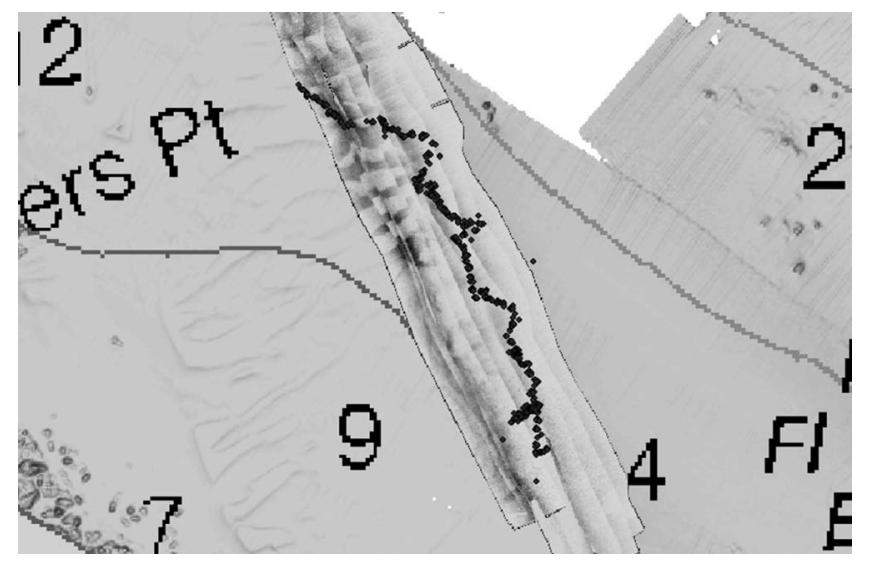

FIG. 3. First track of the ROV-borne video camera on 16 May 2004, superimposed on the sidescan sonar mosaic. The distance between the marked end points of the track is $603 \mathrm{~m}$. the track line. Track lines were corrected for slant-range, layback, and lateral offset, and the position data for each line were smoothed using a speed filter. Each line was then gridded, geo-referenced, and exported from Isis Sonar/Delph Map in geo-referenced Tag(ged) Image File Format (GeoTIFF) $(0.20-\mathrm{m}$ and $0.10-\mathrm{m}$ pixel size, UTM Zone 10, WGS84). Individual track-line TIFF images were imported into TNT Mips GIS software and areas of poor image quality were extracted and removed. Individual track lines were then overlaid to produce a mosaic image.

\section{B. Video-data postprocessing}

Video-data processing was completed using a JVC BRDV600A mini-DV VCR with monitor display. Tapes were reviewed and positional data retrieved using the Horita GPS-3 decoder. The precise locations of squid egg bed observations were recorded in a text file, together with observational data regarding egg bed density, substrate type, and other characteristics. Information from the log sheets and text files was integrated into a database.

\section{Entry of data into geographical information system (GIS)}

Mosaic GeoTIFF images were exported from TNT Mips at 0.20 - and $0.10-\mathrm{m}$ resolutions into ArcGIS 8.3 software (ESRI, Redlands, California). An attribute table that included the parameters logged during the video-camera data analysis was also imported into the same GIS.

Use of ArcGIS enabled both the sonar data and videocamera tracks to be visualized. Individual or multiple sidescan sonar swaths could be displayed, as could video-camera tracks, at the command of the operator. In addition to simple visualization of data, GIS confers other benefits. ${ }^{49}$ These include, for example, displaying the data at different scale sizes, expressing the cursor position in geographical coordinates, overlaying fields with a coordinate grid, measuring the distance between points, marking particular features with a polygon, among other things. Extracted images could also be exported for use outside the GIS.

\section{DATA ANALYSES}

The first analysis involved presence-absence testing; the second, determination of the detection size limit; and the third, abundance estimation of squid eggs over an area.

\section{A. Presence-absence testing}

The primary goal of the testing was to prove, or verify, the association of characteristic features on the sidescan sonar images with the presence of squid egg beds, as well as the absence of squid egg beds in the absence of those same characteristic features. A secondary goal was to establish the size limit of detectability.

Test 1. By means of the ArcMap module within ArcGIS, the sidescan imagery was reviewed in fine detail by one of the co-authors (KF). Geographical areas with dapples or mottling believed characteristic of the presence of squid egg beds were identified. Areas lacking these features were also 

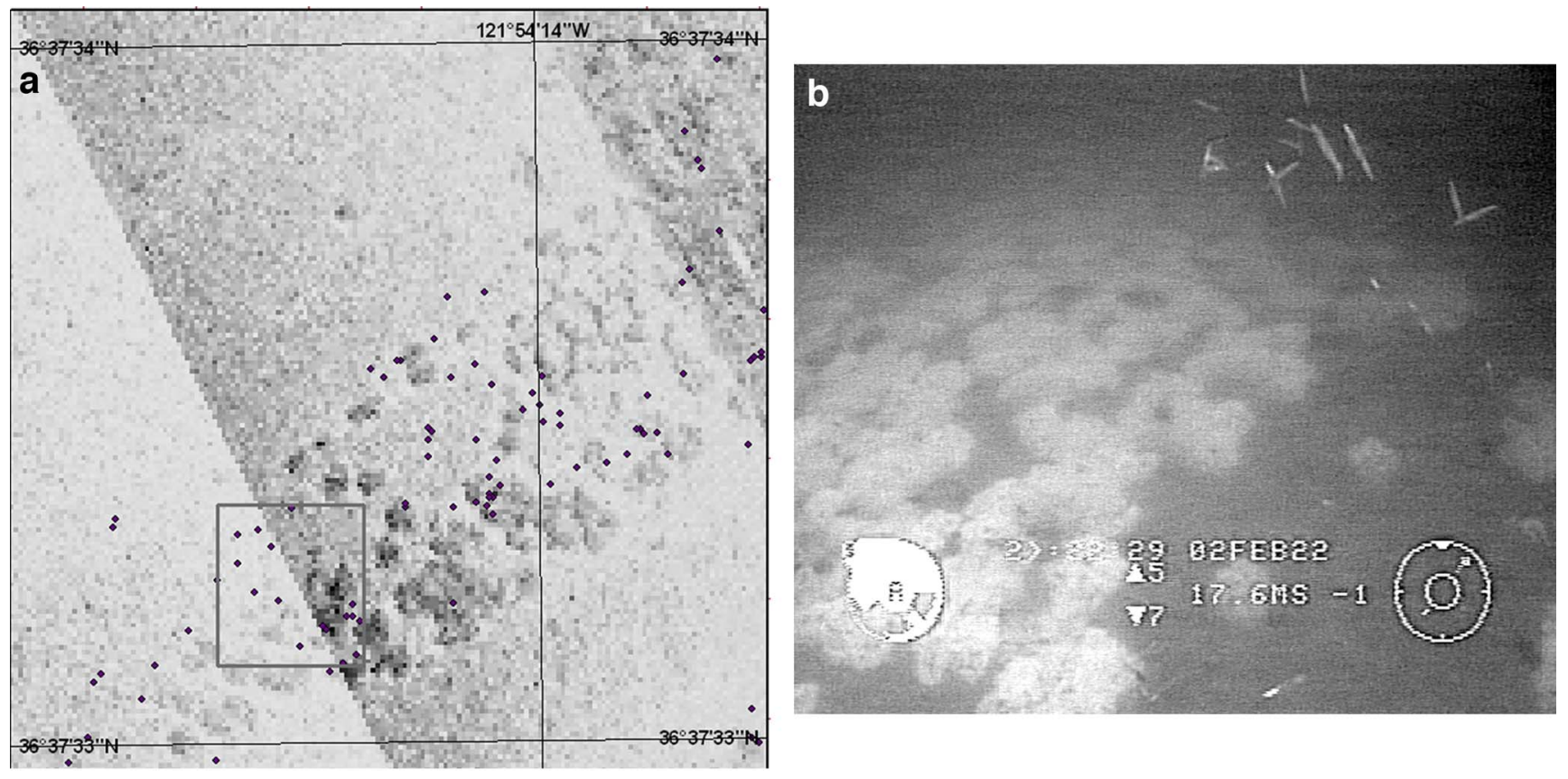

FIG. 4. Pair of images taken from the first test. Excerpt of sidescan sonar mosaic (a), with box indicating the region where the video-camera image (b) was captured. Adult squid are observed in the upper right corner of (b).

identified. A selected example of apparent egg presence is shown in Fig. 4(a). This area was also observed by the ROVborne video camera. Time codes corresponding to the period that the ROV was inside the indicated box in Fig. 4(a) were determined. The particular time codes, together with time codes from another 29 selected regions of interest, were listed without reference to position or sidescan sonar observations to define a first test. These were used blindly by another co-author $(\mathrm{RH})$ when examining the video-camera recordings to describe the presence or absence of squid egg beds. Related observations were made on the size, shape, and distribution of egg mops or beds or other benthos, e.g., kelp fronds, starfish, and sea stars, among other things.

Test 2 . The process of formulating Test 1 was reversed in preparing a second blind test, which also endeavored to define the limits of detectability by sidescan sonar. An example of a video image selected for this test is shown in Fig. 5(a). The second co-author ( $\mathrm{RH})$ reviewed the ROV-borne video-camera tapes in detail, without reference to the sidescan sonar data, choosing a total of 30 representative regions of interest containing or lacking squid egg mops or beds. A list of the corresponding time codes was prepared without
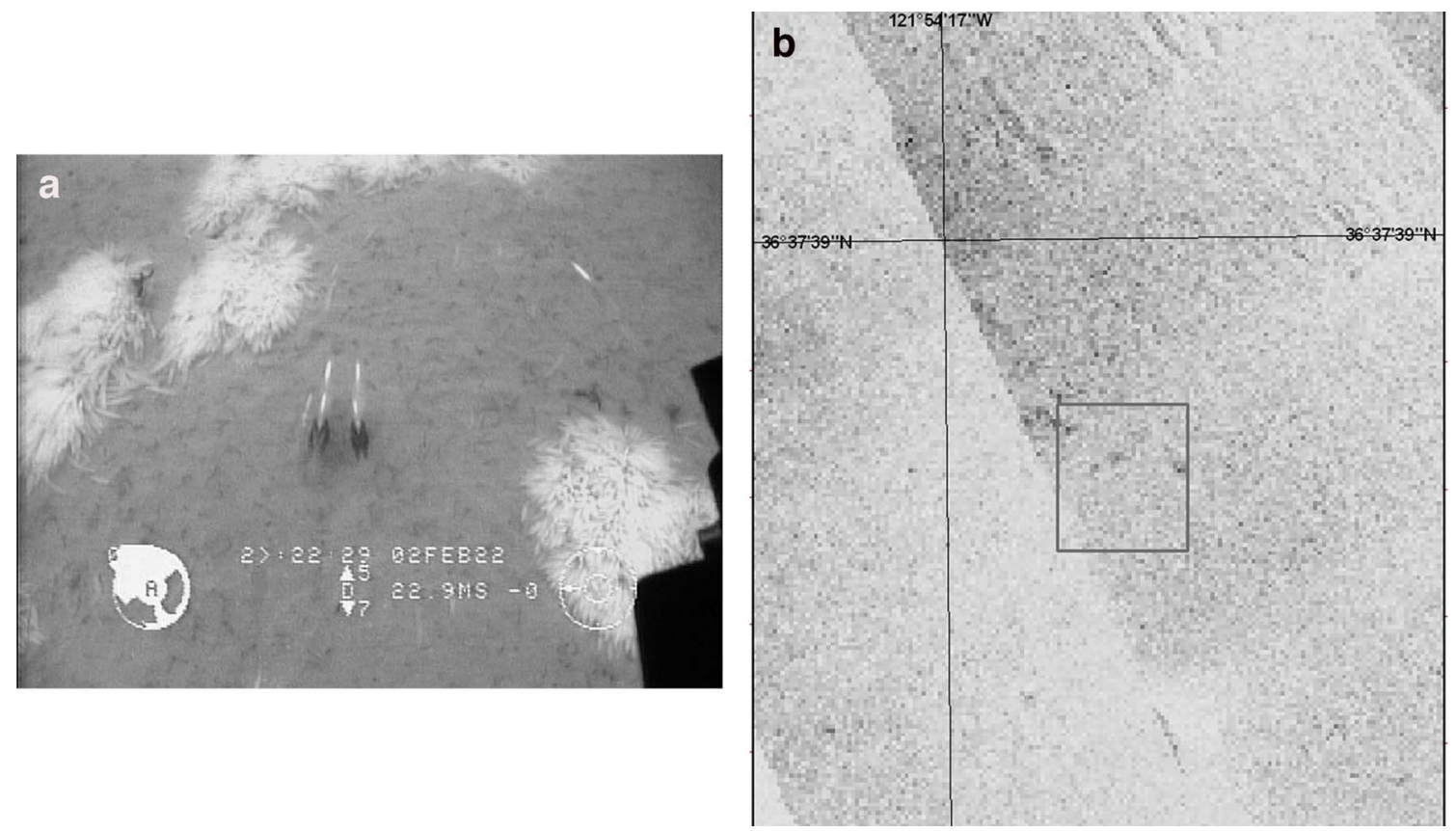

FIG. 5. Pair of images taken from the second test. Video-camera image (a) taken from the indicated area of the corresponding sidescan sonar mosaic excerpt (b). Two mating pairs and two loan squids are also visible in (a). 
information on the video-based observations. The time codes were translated into geographical positions. The first coauthor (KF) then reviewed and interpreted the sidescan sonar imagery in a blind test to describe the markings as believed indicative of the presence or absence of squid egg beds.

The statistical significance of each test was gauged by means of both the binomial and Fisher exact test. ${ }^{50}$

\section{B. Detection limit}

The spatial resolution of the $400-\mathrm{kHz}$ sidescan sonar array is about $10-20 \mathrm{~cm}$ over the range interval $12-23 \mathrm{~m}$. Thus, there will be a lower limit to the size of egg beds that can be detected and identified. Determination of this limit was a secondary goal of the testing. Materials for the determination of the size limit were contained in the presenceabsence testing. The associated video record was examined to establish the sizes of individual egg mops or beds when these were well separated from other clusters. Discrepancies in the statistical testing mentioned in the previous section were given particular attention.

\section{Abundance estimation}

A further analysis was performed to illustrate the quantification process. A quadrat of side length one arcsecond on each side, $30.9 \mathrm{~m}$ in the $\mathrm{N}-\mathrm{S}$ direction and $24.8 \mathrm{~m}$ in the $\mathrm{E}-\mathrm{W}$ direction, was defined, and the fraction of area covered by the squid egg beds was estimated. Assuming a mean diameter of egg capsules of $16 \mathrm{~mm}$, based on several direct measurements, and mean number of eggs per capsule of 150 , based on recent counts of eggs in sampled capsules, the total number, or abundance, of eggs in the quadrat was estimated.

\section{RESULTS}

Positions at which sidescan-sonar-based predictions of squid-egg presence or absence were subsequently, independently judged by reference to the video record are shown in Fig. 6. Agreement of the respective data is indicated by the use of open symbols; disagreement, by filled symbols.

Positions at which video observations of the presence or absence of squid eggs were subsequently, independently interpreted by the sidescan sonar images are shown in Fig. 7. As in the previous figure, agreement is indicated by open symbols and disagreement by filled symbols.

Both the binomial test and the Fisher exact test ${ }^{50}$ were used to test the null hypothesis that the observed agreement in corresponding sonar and video images was due entirely to chance. Contingency tables are presented for the two tests in Tables I and II.

Each test involved 30 trials, each coincidentally yielding 24 positive outcomes in which the presence or absence of eggs was verified by the video record (Table I) or interpreted by the sonar imagery (Table II). The probability that 24 or more outcomes would have agreed was computed according to the binomial distribution assuming a probability of any single outcome being 0.5 . The result was $0.7155 \times 10^{-3}$ for each test.

The Fisher exact test was similarly applied to each set of data. The probability was computed of the distribution of

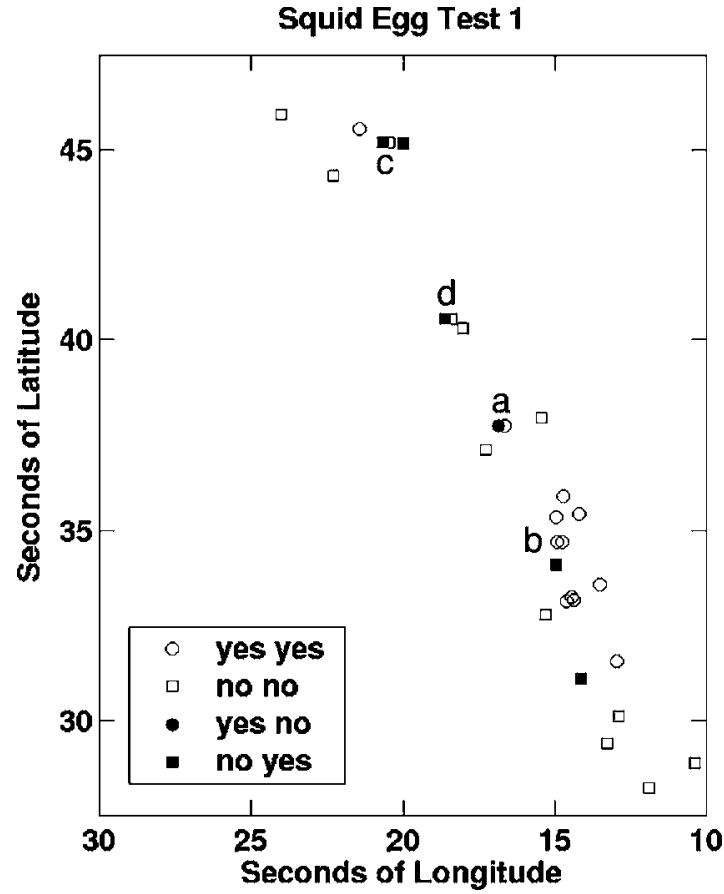

FIG. 6. Positions where sidescan-sonar-based predictions of squid-egg presence or absence were subsequently, independently judged by the video record. Agreement of the respective data is indicated by the use of open symbols; disagreement, by filled symbols.

outcomes shown in the respective tables together with their more extreme cases. The result for the first test (Table I) was $0.5939 \times 10^{-4}$ and for the second (Table II), $0.4082 \times 10^{-7}$.

Thus, at least at the 0.001 level, no matter which test is used, the null hypothesis can be rejected. Characteristic features on the sidescan sonar images can be associated with the presence or absence of squid egg beds.

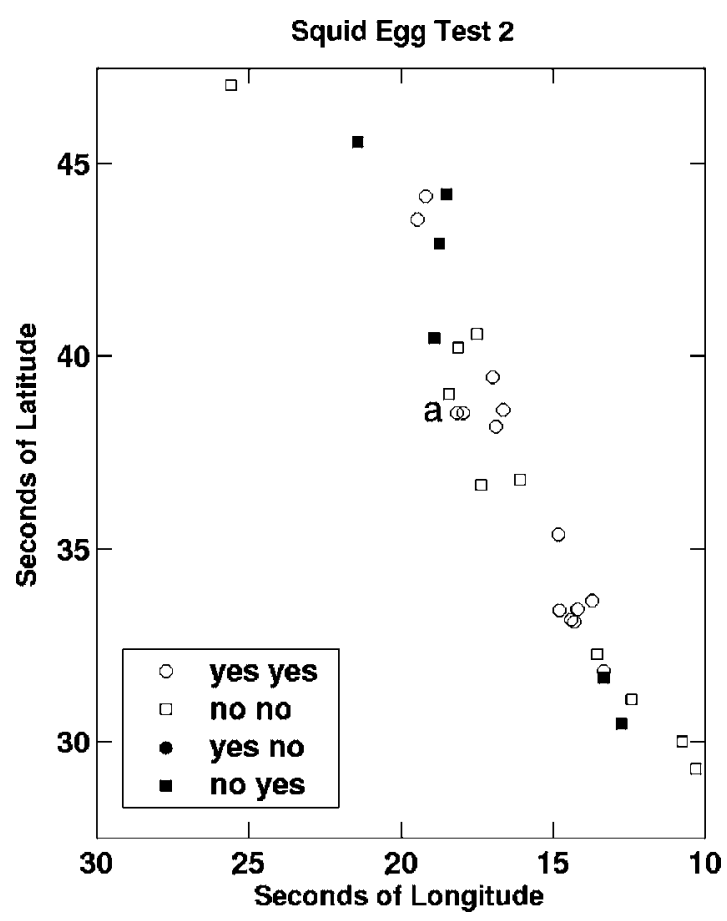

FIG. 7. Positions where video observations of squid-egg presence or absence were subsequently, independently interpreted by the sidescan sonar images. Agreement is indicated by open symbols; disagreement, by filled symbols. 
TABLE I. Contingency table for Test 1 , in which sidescan sonar predictions were made at selected positions, which were subsequently used to specify where to examine the video-camera record.

\begin{tabular}{llccc}
\hline \hline & & \multicolumn{3}{c}{ Sidescan sonar } \\
\cline { 3 - 5 } & & Presence & Absence & Sum \\
\hline Video & Presence & 12 & 5 & 17 \\
camera & Absence & 1 & 12 & 13 \\
& Sum & 13 & 17 & 30 \\
\hline \hline
\end{tabular}

A quadrat has been defined by the one-arc-second area at $\mathrm{N} 36^{\circ} 37^{\prime} 33-34^{\prime \prime}$ and $\mathrm{W} 121^{\circ} 54^{\prime} 14-15^{\prime \prime}$. The sidescan sonar image is shown in Fig. 8. The quadrat area is $764.6 \mathrm{~m}^{2}$. The cumulative area covered by the squid egg beds according to the characteristic dapples was estimated by a graphical method as $49.0 \mathrm{~m}^{2}$, or $6.4 \%$ of the whole. Assuming that the mean diameter of an egg capsule is $16 \mathrm{~mm}$, which was mea-

TABLE II. Contingency table for Test 2, in which video-camera observations were made at selected positions, which were subsequently used to specify where to examine the sidescan sonar images.

\begin{tabular}{llccc}
\hline \hline & & \multicolumn{3}{c}{ Video camera } \\
\cline { 3 - 5 } & & Presence & Absence & Sum \\
\hline Sidescan & Presence & 14 & 0 & 14 \\
sonar & Absence & 6 & 10 & 16 \\
& Sum & 20 & 10 & 30 \\
\hline \hline
\end{tabular}

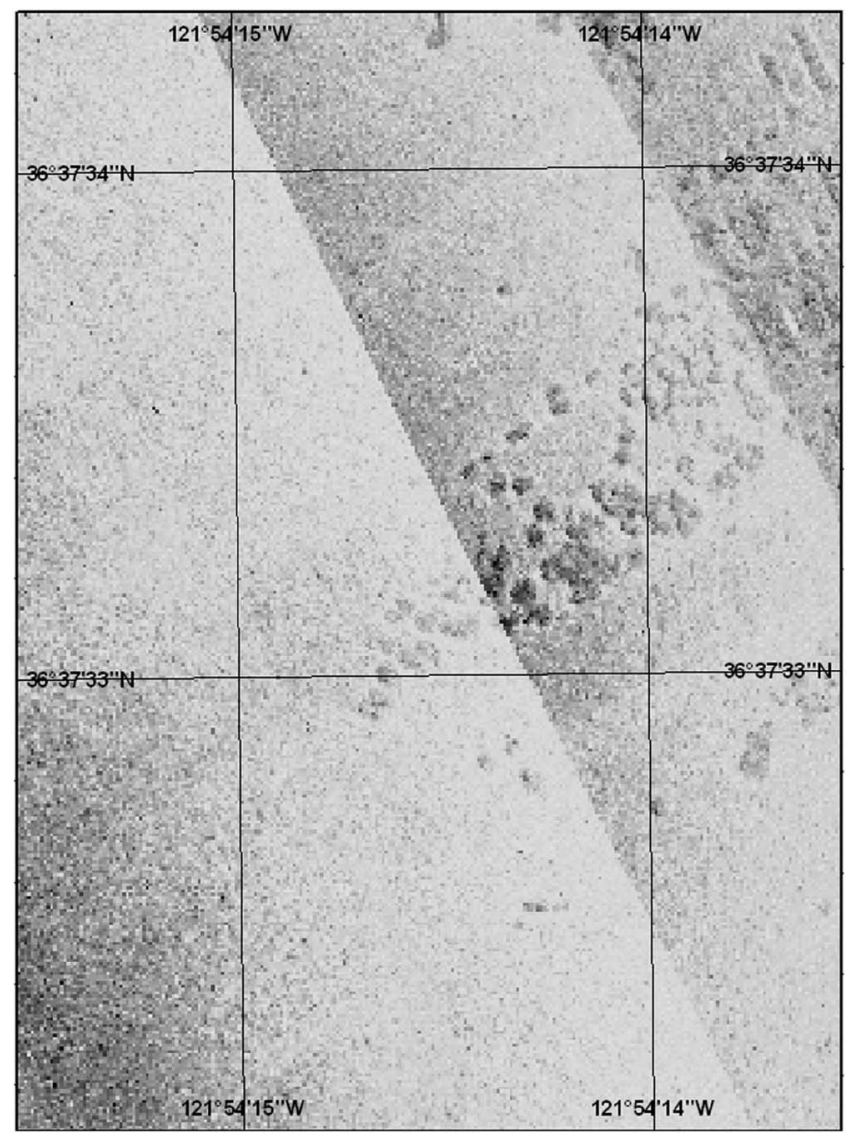

FIG. 8. Sidescan sonar image of a quadrat at N $36^{\circ} 37^{\prime} 33-34^{\prime \prime}$ and W $121^{\circ}$ $54^{\prime} 14-15^{\prime \prime}$ selected for estimating squid-egg abundance. sured for a limited number of retrieved capsules, the estimated number of capsules in the quadrat is $2.44 \times 10^{5}$. Based on an average number of eggs per capsule of 150 , the estimated total number of eggs in the quadrat is $3.65 \times 10^{7}$.

\section{DISCUSSION}

\section{A. Statistical tests}

Characteristic dapple or mottling on the sidescan sonar images at 100 and $400 \mathrm{kHz}$ was first associated with squid egg beds during a cruise in Monterey Bay in May 2003. Data collected one year later, which are analyzed in this work only at the higher frequency, verify the association. The visual images in Figs. 4 and 5 are clearly suggestive, but the robustness of the association has been statistically established through two blind tests.

In the first test, predictions of the presence or absence of squid egg beds were made solely on the basis of the sidescan sonar data, then tested by reference to the video camera recordings. In the second test, areas observed to contain or lack egg beds were used to specify regions of interest in the sidescan sonar images requiring interpretation. Each test was prepared by a co-author and taken by another co-author without knowing the initial sonar interpretation or video observation. The null hypothesis, that the apparent agreement of predictions or interpretations with observations was due entirely to chance, was tested by each of two tests. The null hypothesis was rejected at the 0.001 confidence level by the binomial test and the 0.0001 confidence level by the Fisher exact test.

It is illuminating to examine the failed examples in the two tests. In the first test, in which sonar images were used to specify positions for examination of the video record, there were a total of six failures. Comments made during review of the video record in Test 1 are listed for each instance of disagreement. In only one case did the sidescan sonar image indicate the presence of eggs that was not verified by the video record. In the region of pair a, eggs were not observed along the third ROV track, although their presence was confirmed by the second ROV track. This probably represents a simple miss due to the video camera being oriented in the wrong direction when passing the egg beds. In the other five cases of disagreement, the sidescan sonar images did not indicate the presence of eggs, which were subsequently observed on the video record. The following comments are arranged in order of position from north to south. (i) Two very small mops were observed along the second ROV track, but not along the first ROV track, indicated in pair c. (ii) One tiny egg mop was seen along the first ROV track at the edge of the region of interest. (iii) A few very small, widely dispersed mops were seen along the third ROV track, but not along the second ROV track, in pair d. (iv) A few large clumps, ca. 1-3 m, were observed along the third ROV track at the edge of the region of interest. (v) Two small patches were observed along the third ROV track. In four of the five cases here, the eggs occurred in small mops of diameter less than $0.5 \mathrm{~m}$.

In the second test, there were no instances when the video record indicated the absence of eggs and the sidescan 
sonar imagery suggested their presence. There were six instances when the sidescan sonar imagery failed to register the presence of eggs that had been seen initially on the video record. The following comments were made on these instances during preparation of Test 2: 4-6 small patches $c a$. $0.5 \mathrm{~m}$ each; 1-2 very small egg patches; linear string of eggs; 1 patch $c a$. 10 capsules; 2 patches $c a$. $1 \mathrm{~m}$; and 1 small patch. In four of these cases, the egg mops were, at most, $0.5 \mathrm{~m}$ in diameter. In the other cases, the linear string of eggs was missed, possibly because of its unusual shape; and in the other case, of two patches $c a .1 \mathrm{~m}$ each, possibly because of inaccurate positioning.

\section{B. Size detectability}

In view of the failed examples in the two tests, it appears that egg mops smaller than about $0.5 \mathrm{~m}$ cannot be detected with the system as currently configured and used. This approximate detection limit applies to the use of a $400-\mathrm{kHz}$ sidescan sonar of $0.5-\mathrm{deg}$ beamwidth when towed at 3 -knot speed with a ping rate of $13 / \mathrm{s}$. The resolution is about $10-20 \mathrm{~cm}$ out to about the $25-\mathrm{m}$ range on either side of the towfish. Thus, an object of $50-\mathrm{cm}$ diameter will be spanned by about $3-5$ pixels, with corresponding size in the image. This number is evidently too small to resolve squid egg beds.

The present analysis has only attempted to distinguish the presence and absence of squid eggs. Observed aggregations of eggs ranged in size from roughly circular mops smaller than $0.5 \mathrm{~m}$ to much larger, irregularly shaped clusters of beds. Two such aggregations were measured according to their sidescan sonar image; one was roughly elliptical in shape, with axes 2.7 and $7.4 \mathrm{~m}$; another was cross-shaped, with similar $5-\mathrm{m}$ axes. Egg mops greater than $0.5 \mathrm{~m}$ and egg beds greater than $1 \mathrm{~m}$ have been detected by the sidescan sonar imagery.

Other organisms were also observed in the video record. Examination of the sidescan sonar images at the corresponding locations has failed to reveal identified individual drift kelp fronds (Macrocystis pyrifera) and sea stars, e.g., Pycnopodia helianthoides and Asterina miniata. It is appreciated that these were typically below the detectability size limit, although some kelp strands and the largest Pycnopodia sea stars exceeded $0.5 \mathrm{~m}$ and still did not appear as distinctive features in the acoustic records. The low vertical relief of these targets was probably the primary reason that the sidescan sonar failed to effectively image them.

\section{Positioning issues when comparing diverse data}

Comparison of the sonar and video data, which were collected on different days from different submerged platforms, has also required a closer look at the issues of positioning accuracy and precision. While differential GPS was used, this is updated only at intervals, with an intrinsic accuracy of about $\pm 1-2 \mathrm{~m}$ in the Monterey Bay region. The accuracy in positioning the sidescan sonar towfish (Sec. IV A 1) is poorer since it is towed, and its position must be estimated from the amount of cable deployed and its depth. Further, the towfish is subject to accelerations due to wave action on the towing vessel, which can change the velocity and position of the towfish relative to the dGPS receiver. Making allowance for this, inaccuracies in towfish positioning can be $\pm 5 \mathrm{~m}$, depending on the exact circumstances of towing, including sea state, currents, and direction of ship movement. The accuracy in positioning the ROV-borne video camera is better than that of the towfish, for the ROV is decoupled from vessel motions by having a slack tether, and the ROV is acoustically tracked from the vessel. Thus the positions of the towfish and ROV-borne video camera can each be known to within about $\pm 1-2 \mathrm{~m}$ under good conditions, but closer to $\pm 5 \mathrm{~m}$ under poorer conditions, as with a fresh breeze. In addition, the camera height and orientation influences the field of view, which can differ from the position itself by several meters. Under the worst circumstances, the combined uncertainty of these two can be as much as $\pm 10 \mathrm{~m}$. In comparing the sonar and video observations, agreement was sought to within 3-5 m, occasionally up to about 6-7 $\mathrm{m}$.

Performance of mosaicking also requires comparison of data from transect to transect, if of similar origin. Clues to positioning inaccuracy are evident in the sidescan sonar record. Distortions may be noticed, as in stretched egg bed features in some images. The process of mosaicking can be improved, but the experience of fine-scale optical mosaicking in the laboratory indicates that this is an intricate problem that is inherently three-dimensional in character. ${ }^{51}$ The use of terrain constraints can significantly improve underwater mosaicking, whether optical or acoustical, if the number of images to be combined is not excessive (C. Roman, pers. comm.).

\section{An abundance estimation}

The abundance of squid eggs was estimated for a particular quadrat, yielding the number $3.65 \times 10^{7}$. This quantity is not dissimilar from an estimation performed in a different quadrat the preceding year. This is the first numerical estimate of egg abundance over a region of interest by a rapid, remote, synoptic, noninvasive method. Extension of the quadrat-based estimation to a larger survey area is straightforward.

The authors know of no other acoustic estimate of the abundance of benthic eggs of any squid species. The authors know of two studies reporting abundance estimates of benthic eggs of squid species, but based on SCUBA-diver surveys using principles of random or nonrandom sampling. In a study by Sauer et al., ${ }^{44}$ two basic abundance estimates of eggs of Loligo vulgaris reynaudii were derived, distinguished by the respective statistical analyses: $3.162 \times 10^{9}$ and $1.290 \times 10^{8}$ eggs over respective areas of 74.36 and $1.646 \mathrm{~km}^{2}$. Corresponding numerical densities were $42.52 \mathrm{eggs} / \mathrm{m}^{2}$ in the larger area and $78.32 \mathrm{eggs} / \mathrm{m}^{2}$ in the smaller area. In a study by Moltschaniwskyj and Pecl, ${ }^{52}$ abundance estimates of benthic eggs of southern calamary (Sepioteuthis australis) were derived for two different bays in each of two years. The numbers for one bay were 7.68 $\times 10^{6}$ and $1.14 \times 10^{7}$ eggs over respective areas of 3.67 and 4.19 ha, and $2.47 \times 10^{6}$ and $1.43 \times 10^{6}$ eggs over respective 
areas of 1.35 and 1.36 ha. The corresponding numerical densities were 209 and $272 \mathrm{eggs} / \mathrm{m}^{2}$ for the first bay and 182 and $105 \mathrm{eggs} / \mathrm{m}^{2}$ for the second. These numbers are compared with the numerical density of Loligo opalescens eggs determined by the acoustic method reported here, namely $47720 \mathrm{eggs} / \mathrm{m}^{2}$, that is, about three orders of magnitude greater, although estimated over an area that is less than $1 / 1000$ of the areas in the first study and $1 / 10$ of the areas in the second study. Another major difference is represented by the relative areal coverage. This was partial in the SCUBAdiver surveys, but total in the present acoustic survey using sidescan sonar.

\section{E. Future work}

It should be possible to resolve squid egg beds of dimensions smaller than $0.5 \mathrm{~m}$, as with a more directional, higherfrequency sidescan sonar, with a higher ping rate and a smaller maximum range than was used in the reported work. This would be very useful for extending the detection and identification capability of the method, hence its quantification capability as well. Distinguishing other benthic organisms, e.g., kelp and starfish, would also be useful.

It would be interesting and potentially useful to perform sidescan sonar surveying from other platforms, especially from autonomous underwater vehicles (AUVs). The example of the Remotely Environmental UnitS (REMUS) AUV ${ }^{53}$ comes to mind as a particularly attractive vehicle because it carries sidescan sonars on port and starboard sides as standard equipment. The operating frequency of these is either 600 or $900 \mathrm{kHz}$.

Automatic recognition of squid egg beds on the sidescan sonar image should be possible, as should computation of areas covered by the egg beds. However, can this be done reliably, accurately and with minimal operator intervention?

Combining observation of squid egg beds with that of adult squid in the water column is also important. Acoustic measurement of squid in the water column is eminently feasible, as demonstrated through a number of works cited in Sec. I B. In this way, local population recruitment could be measured directly, and potential future recruitment could be estimated by quantification of the egg beds. The complex of interactions that govern the success of recruitment, including the known attractive effects of egg beds, could help gauge these components as well as others used by fishery managers and population biologists.

It is expected that some basic questions on the biology of Loligo opalescens may be answered through the extended use of acoustic methods. These include, for example, questions on the geographical distribution of egg beds and their association with the benthic habitat. Statistical properties of aggregation can be determined by application of the variogram, the basic structural tool of geostatistics. ${ }^{54,55}$ The potential of acoustics for monitoring extent and rate of egg deposition on the squid spawning grounds is apparent, especially with regard to seasonal and yearly fluctuations that could be correlated eventually with fishery catch records of adults. An example of this approach is reported by Moltschaniwskyj and Pecl, ${ }^{52}$ mentioned in Sec. IX D, who used SCUBA in shallow water to count small egg cases of Sepioteuthis in sea grass. The approach may serve the needs of both managers responsible for the squid fishery and scientists trying to understand the dynamics of squid spawning during an ongoing fishery.

It is a useful exercise to estimate the degree of acoustic coverage that can be achieved by sidescan sonar in a period of hours. If the full track width of sidescan sonar coverage is $100 \mathrm{~m}$ and $100 \%$ overlap is assumed on adjacent, port or starboard parallel tracks, then at a vessel speed of 3 knots, a $5.4-\mathrm{km}$ long transect of effective area $0.27 \mathrm{~km}^{2}$ can be covered in $1 \mathrm{~h}, 2.12 \mathrm{~km}^{2}$ in $8 \mathrm{~h}$. This is a sizable fraction of the total estimated area of the primary spawning grounds in southern Monterey Bay, namely $10 \mathrm{~km}^{2}$.

A fundamental acoustic problem is also waiting to be solved, namely that of determining the backscattering cross section of individual squid egg capsules and how this changes with development phase. This problem might be approached through numerical solution of the wave equation by the finite-element method ${ }^{56,57}$ but as applied to acoustic scattering problems, as in the boundary-element method, e.g., Ref. 58, or infinite-element method, e.g., Ref. 59. Data on the physical properties of individual egg capsules, namely mass density and compressibility, would be required. The scattering problem could also be addressed by measurement, but under controlled conditions.

A second outstanding acoustic problem is modeling scattering from an egg mop or bed. The morphology of the upper surface of a mop or bed is known to be knobbly, with an amplitude of unevenness of order of $1 \mathrm{~cm}$. Interstices are present between neighboring egg capsules. Egg mops and beds may also bend under the influence of currents, including surface-wave action. An appropriate theory of acoustic scattering by such a surface may resemble that for sound scattering by sea ice dendrites at the air-water interface. ${ }^{60}$

Development of a method for calibrating sidescan sonar would also be useful. If the standard-target method ${ }^{61-63}$ could be extended to sidescan sonar, as has recently been accomplished for multibeam sonar, ${ }^{64}$ then the measurements could be performed in an absolute sense. Potential benefits would include demonstrable data quality and maintenance of the same over time, as well as a capability for the intercomparison of data collected with different sidescan sonars.

\section{CONCLUSIONS}

(1) Egg beds of Loligo opalescens in Monterey Bay can be detected, identified, and quantified by high-frequency sidescan sonar imagery.

(2) The lower size limit of detectability of squid egg beds by a $400-\mathrm{kHz}$ sidescan sonar is about $0.5 \mathrm{~m}$.

(3) The method is ready for monitoring applications.

\section{ACKNOWLEDGMENTS}

The authors acknowledge the contributions of many colleagues and organizations. C. Gubala (JC Headwaters Canada) is thanked for lending and operating an EY echo sounder during the first, laboratory-based investigation. A. Henry (California Department of Fish and Game) is thanked 
for valuable support, participation in the first cruise, and facilitating use of R/V Mako, with the following officers and crew: Captain M. Kibby, Engineer R. L. Michalski, R. Hornady, J. DeWitt, T. Tanaka. The following are also thanked for their participation in this first cruise: C. Chan and T. Wadsworth (CDFG); and D. Sullivan, A. Hochstaedter, Y. Yokozawa, and J. Zande (Monterey Peninsula College). Contributions by the following students are acknowledged: A. Rupp (California State University Monterey Bay), and G. Dayhuff, M. Robinson, J. Kibele, D. Williams, S. Okano, and N. Capps (MPC). The following SCUBA divers are thanked for their vital underwater labors: R. Hornady, H. King, C. Dawson, and D. Osorio (CDFG); and S. Clabuesch (University of California at Santa Cruz). G. Shipton (Triton Elics International) is thanked for preparing the sidescan sonar, and J. Condiotty (Simrad) for arranging a loan of the EK60 echo sounder. M. Windham (CDFG) is thanked for logistical support. S. Fangman, NOAA Channel Islands National Marine Sanctuary, is thanked for valuable support, including facilitating the use of R/V Shearwater during the second cruise, with NOAA captains L. Moody and T. Shinn, as well as personal participation during the cruise. CDFG is again thanked for allowing the participation of R. L. Michalski, T. Bishop, K. M. O’Brien, L. M. Laughlin, and D. Porzio during the second cruise. D. Vasey, Santa Barbara City College, is thanked for vital scientific ROV support, as well as allowing the following students to impart their general seagoing expertise in the scientific operations of the cruise: D. Adams, A. Sensabaugh, J. Valenzuela, and R. Remley. M. Parmenter, C. Sellers, and K. Buresch are all thanked for contributions to the figures. The authors are grateful for funding from the National Sea Grant, Essential Fish Habitat Program, and especially the interest of program manager E. Anderson, Sea Grant Project No. NA16RG2273. This is Woods Hole Oceanographic Institution contribution number 11372.

${ }^{1}$ P. R. Boyle and S. Boletzky, "Cephalopod populations: definitions and dynamics," Philos. Trans. R. Soc. London, Ser. B 351, 985-1002 (1996). ${ }^{2}$ G. V. Morejohn, J. T. Harvey, and L. T. Krasnow, "The importance of Loligo opalescens in the food web of marine vertebrates in Monterey Bay, California," in Biological, Oceanographic, and Acoustic Aspects of the Market Squid, Loligo opalescens Berry, edited by C. W. Recksiek and H. W. Frey, Calif. Dep. Fish Game Fish Bull. 169, 67-98 (1978).

${ }^{3}$ W. G. Fields, "The structure, development, food relations, reproduction, and life history of the squid Loligo opalescens Berry," Fish. Bull. 131, 1-108 (1965).

${ }^{4}$ C. M. Dewees and R. J. Price, "Overview of the squid fishery on the Pacific coast of the United States," in Proceedings of the International Squid Symposium, 9-12 August 1981, Boston, Massachusetts (New England Fisheries Development Found., Boston, 1982), pp. 197-212.

${ }^{5}$ M. Vojkovich, "The California fishery for market squid (Loligo opalescens)," CalCOFI Rep. 39, 55-60 (1998).

${ }^{6}$ California Department of Fish and Game, "Market squid fishery management plan: draft," State of California, The Resources Agency, Department of Fish and Game, Marine Region, 7 July 2003.

${ }^{7}$ B. J. Macewicz, J. R. Hunter, N. C. H. Lo, and E. L. LaCasella, "Fecundity, egg deposition, and mortality of market squid (Loligo opalescens)," Fish. Bull. 102, 306-327 (2004).

${ }^{8}$ W. H. H. Sauer, M. J. Smale, and M. R. Lipinski, "The location of spawning grounds, spawning and schooling behaviour of the squid Loligo vulgaris reynaudii (Cephalopoda: Myopsida) off the Eastern Cape Coast, South Africa," Mar. Biol. (Berlin) 114, 97-107 (1992).

${ }^{9}$ J. K. T. Brodziak and A. A. Rosenberg, "A method to assess squid fisheries in the north-west Atlantic," ICES J. Mar. Sci. 50, 187-194 (1993).
${ }^{10}$ G. J. Pierce, N. Bailey, Y. Stratoudakis, and A. Newton, "Distribution and abundance of the fished population of Loligo forbesi in Scottish waters: analysis of research cruise data," ICES J. Mar. Sci. 55, 14-33 (1998).

${ }^{11}$ D. J. Agnew, R. Baranowski, J. R. Beddington, S. des Clers, and C. P. Nolan, "Approaches to assessing stocks of Loligo gahi around the Falkland Islands," Fish. Res. 35, 155-169 (1998).

${ }^{12}$ S. J. Walsh, P. A. Koeller, and W. D. McKone, eds. Proceedings of the International Workshop on Survey Trawl Mensuration. Northwest Atlantic Fisheries Centre, St. John's, Newfoundland, March 18-19, 1991, Canadian Tech. Rep. Fish. Aquat. Sci. 1911, 1-114 (1993).

${ }^{13}$ D. R. Gunderson, Surveys of Fisheries Resources (Wiley, New York, 1993).

${ }^{14}$ T. Okutani and J. McGowan, "Systematics, distribution, and abundance of the epiplanktonic squid (Cephalopoda, Decapoda) larvae of the California Current, April, 1954-March, 1957," Bull. Scripps. Inst. Oceanogr. 14, 1-90 (1969).

${ }^{15}$ M. R. Maxwell, A. Henry, C. D. Elvidge, J. Safran, V. R. Hobson, I. Nelson, B. T. Tuttle, J. B. Dietz, and J. R. Hunter, "Fishery dynamics of the California market squid (Loligo opalescens), as measured by satellite remote sensing," Fish. Bull. 102, 661-670 (2004).

${ }^{16}$ M. Clarke, L. Allcock, and M. B. Santos, "Estimating cephalopod biomass: workshop report," Bull. Mar. Sci. 71, 47-65 (2001).

${ }^{17}$ G. M. Cailliet and D. L. Vaughan, "A review of the methods and problems of quantitative assessment of Loligo opalescens," Biol. Oceanogr. 2, 379$400(1983)$

${ }^{18} \mathrm{~K}$. G. Foote, "Quantitative fisheries research surveys, with special reference to computers," in Computers in Fisheries Research, edited by B. A. Megrey and E. Moksness (Chapman and Hall, London, 1996), pp. 80-112.

${ }^{19}$ R. M. Starr and R. E. Thorne, "Acoustic assessment of squid stocks," in Squid Recruitment Dynamics. The Genus Illex As a Model, the Commercial Illex Species and Influences on Variability, edited by P. G. Rodhouse, E. G. Dawe, R. K. O’Dor, FAO Fish. Tech. Pap. 376, 181-198 (1998).

${ }^{20}$ C. Goss, D. Middleton, and P. Rodhouse, "Investigations of squid stocks using acoustic survey methods," Fish. Res. 54, 111-121 (2001).

${ }^{21}$ M. J. Roberts, M. Barange, M. R. Lipinski, and M. R. Prowse, "Direct hydroacoustic observations of chokka squid Loligo vulgaris reynaudii spawning activity in deep water," S. Afr. J. Mar. Sci. 24, 387-393 (2002).

${ }^{22}$ A. Kawabata, "Target strength measurements of suspended live ommastrephid squid, Todarodes pacificus, and its application in density estimations," Fish. Sci. 71, 63-72 (2005).

${ }^{23}$ D. L. Vaughan and C. W. Recksiek, "An acoustic investigation of market squid, Loligo opalescens," in Biological, Oceanographic, and Acoustic Aspects of the Market Squid, Loligo opalescens Berry, edited by C. W. Recksiek and H. W. Frey, Calif. Dep. Fish Game Fish Bull. 169, 135-147 (1978).

${ }^{24}$ D. L. Vaughan and C. W. Recksiek, "Detection of market squid, Loligo opalescens, with echo sounders," CalCOFI Rep. 20, 40-50 (1979).

${ }^{25}$ K. Jefferts, J. Burczynski, and W. G. Pearcy, "Acoustical assessment of squid (Loligo opalescens) off the Central Oregon coast," Can. J. Fish. Aquat. Sci. 44, 1261-1267 (1987).

${ }^{26}$ J. E. Ehrenberg, "A comparative analysis of in situ methods for directly measuring the acoustic target strength of individual fish," IEEE J. Ocean. Eng. OE-4(4), 141-152 (1979).

${ }^{27}$ C. W. Recksiek and H. W. Frey, in Biological, Oceanographic, and Acoustic Aspects of the Market Squid, Loligo opalescens Berry, Calif. Dep. Fish Game Fish Bull. 169 (1978).

${ }^{28}$ R. F. Hixon, "Loligo opalescens," in Cephalopod Life Cycles, Vol. 1. Species Accounts, edited by P. R. Boyle (Academic, London, 1983), pp. 95114.

${ }^{29}$ G. D. Jackson, "Statolith age estimates of the loliginid squid Loligo opalescens (Mollusca: Cephalopoda): Corroboration with culture data," Bull. Mar. Sci. 54, 554-557 (1994).

${ }^{30}$ J. Butler, D. Fuller, and M. Yaremko, "Age and growth of market squid (Loligo opalescens) off California during 1998," CalCOFI Rep. 40, 191195 (1999).

${ }^{31}$ L. D. Zeidberg and W. M. Hamner, "Distribution of squid paralarvae, Loligo opalescens (Cephalopoda: Myopsida), in the southern California Bight in the three years following the 1997-1998 El Nino," Mar. Biol. (Berlin) 141, 111-122 (2002).

${ }^{32}$ E. S. Hobson, "Spawning in the Pacific coast squid Loligo opalescens," Underwat. Nat. 3, 20-21 (1965).

${ }^{33}$ A. C. Hurley, "Mating behavior of the squid Loligo opalescens," Mar. Behav. Physiol. 4, 195-203 (1977).

${ }^{34}$ R. T. Hanlon, "Mating systems and sexual selection in the squid Loligo: 
How might commercial fishing on spawning squids affect them?" CalCOFI Rep. 39, 92-100 (1998).

${ }^{35}$ R. R. Leos, "The biological characteristics of the Monterey Bay squid catch and the effect of a two-day-per-week fishing closure," CalCOFI Rep. 39, 204-211 (1998).

${ }^{36}$ J. W. Forsythe, N. Kangas, and R. T. Hanlon, "Does the California Market Squid, Loligo opalescens, spawn naturally during the day or at night? A note on the successful use of ROVs to obtain basic fisheries biology data," Fish. Bull. 102, 389-392 (2004).

${ }^{37}$ R. T. Hanlon, N. Kangas, and J. W. Forsythe, "Egg capsule deposition and how behavioral interactions influence spawning rate in the squid Loligo opalescens in Monterey Bay, California," Mar. Biol. (Berlin) 145, 923 930 (2004).

${ }^{38}$ A. Okabe, B. Boots, K. Sugihara, and S. N. Chiu, Spatial Tessellations: Concepts and Applications of Voronoi Diagrams (Wiley, Chichester, 2000).

${ }^{39}$ J. A. McGowan, "Observations on the sexual behavior and spawning of the squid, Loligo opalescens, at La Jolla, California," Calif. Fish and Game 40, 47-54 (1954).

${ }^{40}$ L. D. Zeidberg, W. Hamner, K. Moorehead, and E. Kristof, "Egg masses of Loligo opalescens (Cephalopoda: Myopsida) in Monterey Bay, California following the El Nino event of 1997-1998," Bull. Mar. Sci. 74, 129 141 (2004).

${ }^{41}$ P. G. Rodhouse, E. G. Dawe, and R. K. O'Dor, in Squid Recruitment Dynamics. The Genus Illex as a Model, the Commercial Illex Species and Influences on Variability, FAO Fish. Tech. Pap. 376 (1998).

${ }^{42}$ J. P. Fish and H. A. Carr, Sound Underwater Images, A Guide to the Generation and Interpretation of Side Scan Sonar Data, 2nd ed. (Lower Cape Publishing, Orleans, MA, 1990).

${ }^{43}$ J. P. Fish and H. A. Carr, Sound Reflections, Advanced Applications of Side Scan Sonar (Lower Cape Publishing, Orleans, MA, 2001).

${ }^{44}$ W. H. H. Sauer, C. McCarthy, M. J. Smale, and A. S. Koorts, "An investigation of the egg distribution of the chokka squid, Loligo vulgaris reynaudii, in Krom Bay, South Africa," Bull. Mar. Sci. 53, 1066-1077 (1993).

${ }^{45}$ L. N. Andersen, "The new Simrad EK60 scientific echo sounder system," J. Acoust. Soc. Am. 109, 2336 (2001).

${ }^{46}$ H. Bodholt, H. Nes, and H. Solli, "A new echo-sounder system," Proc. Inst. Acoust. 11(3), 123-130 (1989).

${ }^{47}$ K. G. Foote and G. Stefánsson, "Definition of the problem of estimating fish abundance over an area from acoustic line-transect measurements of density," ICES J. Mar. Sci. 50, 369-381 (1993).

${ }^{48}$ H. R. Skjoldal, P. H. Wiebe, and K. G. Foote, "Sampling and experimental design," in ICES Zooplankton Methodology Manual, edited by R. Harris, P. Wiebe, J. Lenz, H. R. Skjoldal, and M. Huntley (Academic, San Diego, 2000), pp. 33-53.

${ }^{49}$ J. Breman, ed. Marine Geography: GIS for the Oceans and Seas (ESRI Press, Redlands, CA, 2002).

${ }^{50}$ J. H. Zar, Biostatistical Analysis, 4th ed. (Prentice-Hall, Upper Saddle River, NJ, 1999).

${ }^{51}$ R. Preston, "Capturing the unicorn," The New Yorker 81(8), 28-33 (2005).

${ }^{52}$ N. A. Moltschaniwskyj and G. T. Pecl, "Small-scale spatial and temporal patterns of egg production by the temperate lolilginid squid Sepioteuthis australis," Mar. Biol. (Berlin) 142, 509-516 (2003).

${ }^{53}$ B. R. Allen, R. Stokey, T. Austin, N. Forrester, R. Goldsborough, M. Purcell, and C. von Alt, "REMUS: a small, low cost AUV; system description, field trials and performance results," Proc. MTS/IEEE Oceans'97 Conf., Vol. 2, pp. 994-1000 (1997).

${ }^{54}$ N. A. C. Cressie, Statistics for Spatial Data (Wiley, New York, 1991).

${ }^{55}$ J. Rivoirard, J. Simmonds, K. G. Foote, P. Fernandes, and N. Bez, Geostatistics for Estimating Fish Stock Abundance (Blackwell Science, Oxford, 2000)

${ }^{56}$ O. C. Zienkiewicz and R. L. Taylor, The Finite Element Method, 5th ed. (Butterworth Heinemann, Oxford, 2000).

${ }^{57}$ D. S. Burnett, Finite Element Analysis: from Concepts to Applications (Addison-Wesley, Reading, MA, 1988).

${ }^{58}$ D. T. I. Francis, "A gradient formulation of the Helmholtz integral equation for acoustic radiation and scattering," J. Acoust. Soc. Am. 93, 17001709 (1993).

${ }^{59}$ D. S. Burnett, "A three-dimensional acoustic infinite element based on a prolate spheroidal multipole expansion," J. Acoust. Soc. Am. 96, 27982816 (1994).

${ }^{60}$ T. K. Stanton, K. C. Jezek, and A. J. Gow, "Acoustical reflection and scattering from the underside of laboratory grown sea ice: Measurements and predictions," J. Acoust. Soc. Am. 80, 1486-1494 (1986).

${ }^{61}$ K. G. Foote, "Optimizing copper spheres for precision calibration of hydroacoustic equipment," J. Acoust. Soc. Am. 71, 742-747 (1982).

${ }^{62}$ K. G. Foote, "Maintaining precision calibrations with optimal copper spheres," J. Acoust. Soc. Am. 73, 1054-1063 (1983).

${ }^{63}$ K. G. Foote, H. P. Knudsen, G. Vestnes, D. N. MacLennan, and E. J. Simmonds, "Calibration of acoustic instruments for fish density estimation: a practical guide," ICES Coop. Res. Rep. 144 (1987), 69 pp.

${ }^{64}$ K. G. Foote, D. Chu, T. R. Hammar, K. C. Baldwin, L. A. Mayer, L. C. Hufnagle, Jr., and J. M. Jech, "Protocols for calibrating multibeam sonar," J. Acoust. Soc. Am. 117, 2013-2027 (2005). 